\title{
Vitamin D levels in patients admitted to the intensive care unit and the association with organ dysfunction and glutamine levels
}

\author{
F Seedat, ${ }^{1}$ MB BCh, Dip HIV Man (SA), MMed (Int Med), FCP (SA); G K Schleicher, ${ }^{1}$ MB BCh, DTM\&H, MMed (Int Med), FCP (SA), \\ FCCP, Cert Pulmonology (SA); P Gaylard, ${ }^{2} \mathrm{PhD}$; R Blaauw, ${ }^{3} \mathrm{PhD}$ (Nutrition) \\ ${ }^{1}$ Wits Donald Gordon Medical Centre ICU, Johannesburg, South Africa \\ ${ }^{2}$ Data Management and Statistical Analysis, Johannesburg, South Africa \\ ${ }^{3}$ Division of Human Nutrition, Department of Global Health, Faculty of Medicine and Health Sciences, Stellenbosch University, Cape Town, \\ South Africa
}

Corresponding author: F Seedat (faheem@global.co.za)

\begin{abstract}
Background. Vitamin D deficiency is common in intensive care unit (ICU) patients (50-82\%) and is associated with multi-organ dysfunction. Vitamin D deficiency alters pathways of glutamine metabolism in critical illness, but the impact of vitamin D status on glutamine levels is poorly characterised.

Objectives. To assess the prevalence of vitamin D deficiency and its association with organ dysfunction and glutamine levels in a South African (SA) ICU.

Methods. Records of 103 adult patients admitted to the Wits Donald Gordon Medical Centre ICU, Johannesburg, SA were retrospectively reviewed. 25-hydroxyvitamin $\mathrm{D}(25(\mathrm{OH}) \mathrm{D})$ and glutamine levels were measured on admission. The association between admission vitamin D levels and glutamine levels, illness severity scores, organ support and outcomes was examined.

Results. On ICU admission, 66\% (68/103) of patients were vitamin D deficient ( $<20 \mathrm{ng} / \mathrm{mL})(95 \%$ confidence interval (CI) 56 - 75). Vitamin D deficiency was significantly associated with mechanical ventilation $(40 \% \mathrm{v} .14 \%)(p=0.013)$ and a higher median sequential organ failure assessment (SOFA) score on admission (6 (interquartile range (IQR) 3 - 8) v. 4 (IQR 2 - 6)) ( $p=0.047)$ and on day 7 (5 (IQR 2 - 10) v. 2 $(\mathrm{IQR} 1-4))(p=0.017)$. Median admission serum glutamine levels were $481 \mu \mathrm{mol} / \mathrm{L}$, with $38 \%$ deficient $(<420 \mu \mathrm{mol} / \mathrm{L})(95 \% \mathrm{CI} 28-48)$. Vitamin D deficiency status on admission was not significantly associated with median admission glutamine levels $(p=0.66)$.

Conclusions. Vitamin D deficiency is common in ICU patients in SA. Deficient patients were more severely ill and required more respiratory support. No significant relationship between deficiency and median glutamine levels was noted.
\end{abstract}

S Afr Med J 2020;110(11):1128-1133. https://doi.org/10.7196/SAMJ.2020.v110i11.14726

The prohormone vitamin $\mathrm{D}$ is best known for its key role in the metabolism of calcium and phosphate. ${ }^{[1]}$ In critically ill patients, the potential to influence outcome through its pleiotropic effects on bone, muscle, cardiac and immunological function (where it is stimulatory to the innate but immunomodulatory to the adaptive immune system) has created interest in the use of vitamin D in the intensive care unit (ICU) among intensivists. ${ }^{[2,3]}$

Vitamin D deficiency is highly prevalent in ICU patients, with a prevalence of $50-82 \%$, and is associated with increased inflammatory markers, multi-organ dysfunction, immune dysregulation and poorer outcomes. ${ }^{[1,2,4-7]}$ Elevated inflammatory markers, particularly C-reactive protein (CRP) and procalcitonin (PCT), occur with vitamin D deficiency ${ }^{[8]}$ A Brazilian cohort of critically ill patients with 25-hydroxyvitamin D (25(OH)D) levels $<12 \mathrm{ng} / \mathrm{mL}$ had increased organ system dysfunction and a greater change in sequential organ failure assessment (SOFA) score. ${ }^{[9,10]}$ Furthermore, observational studies have shown an independent association between vitamin $\mathrm{D}$ deficiency and mortality. ${ }^{[9,10]}$ In meta-analyses examining vitamin D deficiency among critically ill patients, increased rates of infection, sepsis and mortality have been noted. ${ }^{[5,7]}$

Randomised controlled trials (RCTs) that have investigated vitamin $\mathrm{D}$ supplementation in deficient critically ill patients have shown little benefit. The VITdAL-ICU (Effect of High-Dose Vitamin $\mathrm{D}_{3}$ on Hospital Length of Stay in Critically Ill Patients with Vitamin D Deficiency) RCT that assessed outcomes of critically ill vitamin D-deficient patients following vitamin D supplementation did not demonstrate improvement in length of hospital stay, hospital mortality or 6-month mortality, except in severely vitamin D-deficient patients $(25(\mathrm{OH}) \mathrm{D}<12 \mathrm{ng} / \mathrm{mL})$, where mortality was reduced (hazard ratio (HR) 0.56 (95\% confidence interval (CI) 0.35 - 0.90)). ${ }^{[1]}$ Moreover, in patients supplemented with vitamin $\mathrm{D}$, median inflammatory marker levels were reduced on day 28 compared with placebo (CRP $51 \mathrm{v}$. $32 \mathrm{mg} / \mathrm{L}(p=0.04)$; PCT 0.2 v. $0.1 \mathrm{ng} / \mathrm{mL}(p=0.05)) .{ }^{[1]]}$ In contrast, no improved 90-day mortality outcome was noted in the recent VIOLET (Early High-Dose Vitamin $\mathrm{D}_{3}$ for Critically Ill, Vitamin D-Deficient Patients) double-blind, placebo-controlled RCT of early vitamin $\mathrm{D}_{3}$ supplementation with a single enteral dose of $540000 \mathrm{IU}$ vitamin $\mathrm{D}_{3}$ compared with placebo in vitamin D-deficient $(25(\mathrm{OH}) \mathrm{D}<20 \mathrm{ng} / \mathrm{mL})$ critically ill patients. ${ }^{[12]}$

Recent data have illustrated that vitamin D deficiency $(25(\mathrm{OH}) \mathrm{D}$ $<15 \mathrm{ng} / \mathrm{mL}$ ) during early critical illness is crucial in the regulation of glutathione and glutamate pathways. Both pathways influence glutamine metabolism and ultimately serum glutamine levels. ${ }^{[13]}$ There is no consensus with regard to the data examining glutamine supplementation in critically ill patients. Some studies have shown reduced infection rates, ICU and hospital stay, and mortality 
after vitamin D supplementation, while other studies have noted increased mortality rates. ${ }^{[14-18]}$ Experts have argued that the benefits of glutamine supplementation in critically ill patients cannot yet be discounted, as a $\mathrm{U}$-shaped curve is noted when comparing glutamine levels with outcomes. Serum glutamine levels should be targeted to a specific range for beneficial effects to be noted. Hence, understanding initial admission glutamine levels in patients admitted to the ICU is necessary to enable treating physicians to identify patients who may benefit from glutamine supplementation. ${ }^{[19]}$ As vitamin D deficiency may influence serum glutamine levels, it is of value to elucidate the interaction between vitamin $\mathrm{D}$ and glutamine metabolism in critically ill patients to determine the effect of vitamin D deficiency on glutamine levels and the potential threshold for glutamine supplementation.

There are few South African (SA) data examining the prevalence of vitamin D deficiency and the impact on clinical outcomes, inflammatory markers and organ dysfunction in critically ill patients. This is of particular interest, as SA is a high ultraviolet B (UVB) light region, where rates of vitamin $\mathrm{D}$ deficiency are thought to be low. ${ }^{[20]}$ Furthermore, to our knowledge, no studies have compared baseline vitamin $\mathrm{D}$ and glutamine levels, despite evidence suggesting a metabolic link between the two. Due to the heterogeneous multiracial and multi-ethnic patient population in SA, this lack of data represents an opportunity to add to the current growing international literature on vitamin $\mathrm{D}$ and glutamine in critically ill patients.

\section{Methods}

This observational retrospective study reviewed the clinical and biochemical records of medical and surgical patients admitted to the Wits Donald Gordon Medical Centre ICU in Johannesburg, SA, from January 2018 to July 2018. Adult patients $\geq 18$ years of age with baseline data recorded within 24 hours of admission, and who were admitted for a minimum of 3 days, were included. Patients for whom data were incomplete or insufficient, or whose necessary biochemical parameters were not measured, were excluded.

\section{Study definitions and measures}

Patients included in the study were defined as those admitted to the ICU for either acute organ support or acute postoperative care after major surgery. The following were extracted from clinical records: demographics, anthropometrical measurements, body mass index (BMI), (classified by the World Health Organization (WHO)), ${ }^{[21]}$ clinical diagnosis based on the patient's profile when admitted to the ICU (chronic liver disease, colorectal cancer (CRC), hepatobiliary cancer, chronic kidney disease (CKD) and other diagnoses), primary reason for admission to the ICU (medical or surgical), acute physiology and chronic health evaluation (APACHE) II score on admission and SOFA scores on admission and day 7, duration of ICU and hospital stay, need for organ support (ventilation, vasopressors or inotrope agents and haemodialysis) and mortality outcome. The results of inpatient blood sampling, i.e. admission biochemistry, admission glutamine and 25(OH)D levels, were also recorded.

Serum levels of $25(\mathrm{OH}) \mathrm{D}$ were measured to evaluate vitamin D status due to its greater reliability, longer half-life and greater plasma concentrations. ${ }^{[1,22]}$ The Abbott Architect 25(OH)D chemiluminescent microparticle immunoassay (Abbott Laboratories, Germany) was used to measure serum $25(\mathrm{OH}) \mathrm{D}$ concentrations. Serum $25(\mathrm{OH}) \mathrm{D}$ levels $<20 \mathrm{ng} / \mathrm{mL}$ were classified as deficient, $20-30 \mathrm{ng} / \mathrm{mL}$ as insufficient and $>30 \mathrm{ng} / \mathrm{mL}$ as sufficient. ${ }^{[1,2,13]}$ Serum glutamine levels were analysed, using liquid chromatography-mass spectrometry, at the central analytical facilities, Stellenbosch University, SA. All samples were centrifuged within 30 minutes and stored at $-80^{\circ} \mathrm{C}$ until analysed. Glutamine levels $<420 \mu \mathrm{mol} / \mathrm{L}$ were categorised as deficient. ${ }^{[24]}$

\section{Sample size}

Sample size estimation is based on key research questions to be answered, in this case: (i) estimation of the prevalence of vitamin D deficiency; and (ii) association between categorised baseline vitamin D levels and categorical variables. For the first question, based on worst-case (for sample size) estimates of $50 \%, 5 \%$ precision and the $95 \%$ CI level, a sample size of $n=385$ would be required; the actual sample size of $n=103$ corresponds with a precision of $9.7 \%$ - not $5 \%$. For the second question, Fisher's exact test is required for most tests of association $(2 \times 2$ tables). For the detection of a medium effect size $(w=0.3)$, should it exist, with $80 \%$ power at a significance level of $p<0.05$, a minimum sample size of $n=87$ is required. The actual sample size of $n=103$ allows the detection of a slightly larger effect size. Sample size calculations were carried out in $\mathrm{G}^{*}$ Power. ${ }^{[25]}$

\section{Data analysis}

For comparison with the vitamin D-deficient group, the insufficient and sufficient groups were combined owing to small group sizes. The $\chi^{2}$ test was used to assess the relationship between categorised vitamin $\mathrm{D}$ levels and categorical variables. Fisher's exact test was used for $2 \times 2$ tables. The relationship between categorised vitamin $\mathrm{D}$ levels and continuous variables was assessed by the Wilcoxon rank sum test. The correlation between vitamin D and glutamine levels was assessed by Spearman's correlation coefficient. Data analysis was carried out using SAS version 9.4 for Windows (Microsoft, USA). A significance level of $p<0.05$ was used.

\section{Ethical approval}

The University of the Witwatersrand Human Research Ethics Committee approved this study (ref. no. M181129).

\section{Results}

From January 2018 to July 2018, 120 adult patients met the study inclusion criteria. Of these, 17 were subsequently excluded owing to insufficient clinical information, leaving a final total of 103 study patients. The median age was 57 years (interquartile range (IQR) 44 - 67). An equal representation of genders and medical and surgical patients was seen. The median admission APACHE II and SOFA scores were 13 (IQR 8 - 18) and 5 (IQR 5 - 7), respectively. The largest group of patients had chronic liver dysfunction (36\%); of these, $49 \%$ had acute liver failure or acute decompensation of chronic liver failure, while 35\% had undergone liver transplantation. The second largest group of patients had cancer: $27 \%$ had CRC and were admitted after major colorectal surgery, whereas $7 \%$ had hepatobiliary cancer and were admitted after pancreaticoduodenectomy. Among those with CKD, $64 \%$ were admitted with sepsis, while $36 \%$ had undergone renal transplantation. Admission demographic, anthropometric and clinical characteristics are shown in Table 1.

On admission, $66 \%$ of this cohort were vitamin D deficient (95\% CI 56 - 75) (Fig. 1). When these patients were compared by race, gender, BMI, primary diagnosis and reason for ICU admission, no significant differences between groups were observed (Table 1). In this cohort, the prevalence of glutamine deficiency was $38 \%$ (95\% CI 28 - 48); however, there was no significant association between admission median serum glutamine levels and vitamin D status (Spearman's Rho $-0.097 ; p=0.32$ ) (Table 2). 
On admission to the ICU, a significantly higher median SOFA score was noted in the vitamin D-deficient group (Table 2). However, no significant differences between the two groups in median levels of inflammatory markers, renal function and liver function were seen
(Table 2). The use of mechanical ventilation was significantly higher in the vitamin D-deficient group ( $p=0.013$ ), while increased vasopressor use was not significant ( $p=0.069$ ) (Fig. 2).

In the entire cohort, the median length of ICU stay was 7 (IQR 5 - 10) days and the

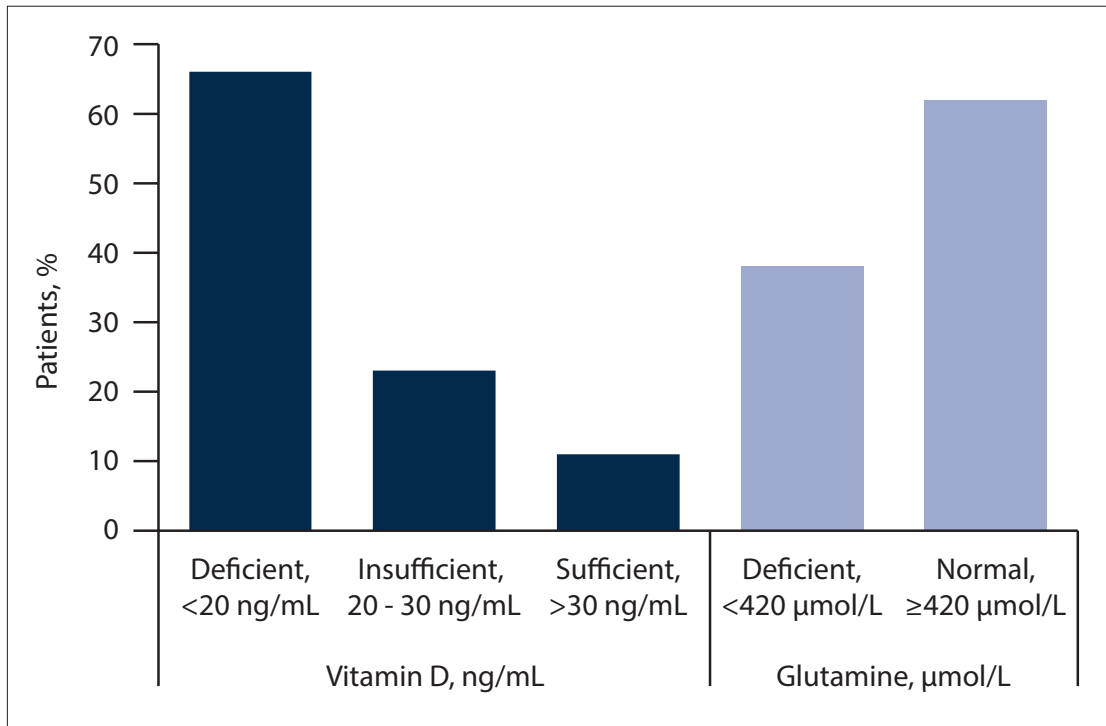

Fig. 1. Vitamin D and glutamine status on admission to the ICU $(\mathrm{N}=103)$.

mortality rate $15 \%$. Comparing patients as vitamin D-deficient v. insufficient/sufficient, showed no significant difference in outcome measures. However, in the vitamin D-deficient group the median day 7 SOFA score remained significantly higher (Table 3 ).

\section{Discussion}

In this SA cohort, $66 \%$ of patients admitted to the ICU were vitamin D deficient and $38 \%$ were glutamine deficient. Vitamin D-deficient patients had higher median SOFA scores on admission and on day 7 of ICU stay. They also required increased mechanical ventilation; however, no impact on median ICU length of stay or mortality was noted. There was no significant relationship between vitamin $\mathrm{D}$ and glutamine status on admission.

We noted a high prevalence of vitamin D deficiency, which was similar to that in other studies. ${ }^{[1,2,4-7]}$ Vitamin D deficiency among ICU patients remained high, even with high UVB light exposure in SA. ${ }^{[20]}$ This result is similar to results in other studies, where, regardless of the degree of UVB light exposure, the prevalence of vitamin $\mathrm{D}$

Table 1. Patient characteristics compared with vitamin D status on admission $(N=103)$

\begin{tabular}{|c|c|c|c|c|}
\hline Patient characteristics & Total $(N=103), n(\%)$ & $\begin{array}{l}\text { Vitamin D deficient, } \\
<20 \mathrm{ng} / \mathrm{mL} \\
(n=68), n(\%)\end{array}$ & $\begin{array}{l}\text { Vitamin D insufficient/ } \\
\text { sufficient, } \geq 20 \mathrm{ng} / \mathrm{mL} \\
(n=35), n(\%)\end{array}$ & $p$-value \\
\hline \multicolumn{5}{|l|}{ Age, years } \\
\hline$\leq 65$ & $74(72)$ & $49(72)$ & $25(71)$ & $>0.99$ \\
\hline$>65$ & $29(28)$ & $19(28)$ & $10(29)$ & \\
\hline \multicolumn{5}{|l|}{ Ethnicity } \\
\hline White & $67(65)$ & $42(62)$ & $25(71)$ & 0.58 \\
\hline Black & $21(20)$ & $16(24)$ & $5(14)$ & \\
\hline Asian & $13(13)$ & $9(13)$ & $4(11)$ & \\
\hline Coloured & $2(2)$ & $1(1)$ & $1(3)$ & \\
\hline \multicolumn{5}{|l|}{ Gender } \\
\hline Male & $51(49)$ & $38(56)$ & $13(37)$ & 0.096 \\
\hline Female & $52(51)$ & $30(44)$ & $22(63)$ & \\
\hline \multicolumn{5}{|l|}{ Body mass index } \\
\hline Underweight $\left(<18.5 \mathrm{~kg} / \mathrm{m}^{2}\right)$ & $4(4)$ & $28(41)$ & $17(49)$ & $0.40^{\dagger}$ \\
\hline Normal weight $\left(18.5-25 \mathrm{~kg} / \mathrm{m}^{2}\right)$ & $41(40)$ & & & \\
\hline Overweight (25.1 - $\left.30 \mathrm{~kg} / \mathrm{m}^{2}\right)$ & $32(31)$ & $20(29)$ & $12(34)$ & \\
\hline Obese $\left(>30 \mathrm{~kg} / \mathrm{m}^{2}\right)$ & $26(25)$ & $20(29)$ & $6(17)$ & \\
\hline \multicolumn{5}{|l|}{ Reason for admission } \\
\hline Medical & $50(48)$ & $35(51)$ & $15(43)$ & 0.53 \\
\hline Surgical & $53(52)$ & $33(49)$ & $20(57)$ & \\
\hline \multicolumn{5}{|l|}{ Underlying diagnosis } \\
\hline Chronic liver disease & $37(36)$ & $29(43)$ & $8(23)$ & 0.27 \\
\hline Colorectal cancer & $28(27)$ & $15(22)$ & $13(37)$ & \\
\hline Chronic kidney disease & $14(14)$ & $8(12)$ & $6(17)$ & \\
\hline Hepatobiliary cancer & $7(7)$ & $5(7)$ & $2(6)$ & \\
\hline Other & $17(17)$ & $11(16)$ & $6(17)$ & \\
\hline
\end{tabular}




\begin{tabular}{|c|c|c|c|}
\hline & $\begin{array}{l}\text { Vitamin D deficient }(<20 \mathrm{ng} / \mathrm{mL}) \text {, } \\
\text { median (IQR) }\end{array}$ & $\begin{array}{l}\text { Vitamin D insufficient/sufficient } \\
(\geq 20 \mathrm{ng} / \mathrm{mL}), \text { median }(\mathrm{IQR})\end{array}$ & $p$-value \\
\hline SOFA & $6(3-8)$ & $4(2-6)$ & 0.047 \\
\hline APACHE II & $15(8-19)$ & $11(8-16)$ & 0.28 \\
\hline C-reactive protein, $\mathrm{mg} / \mathrm{dL}$ & $28(7-74)$ & $20(4-92)$ & 0.76 \\
\hline Procalcitonin, $\mu \mathrm{g} / \mathrm{L}$ & $0.72(0.23-1.96)$ & $0.85(0.24-1.74)$ & 0.99 \\
\hline Urea, mmol/L & $7.0(4.5-16.3)$ & $5.8(4.2-13.7)$ & 0.44 \\
\hline Creatinine, $\mu \mathrm{mol} / \mathrm{L}$ & $100(74-202)$ & $94(62-290)$ & 0.69 \\
\hline Albumin, $g / L$ & $31(27-33)$ & $29(22-35)$ & 0.63 \\
\hline Bilirubin, $\mu \mathrm{mol} / \mathrm{L}$ & $21(10-39)$ & $13(9-24)$ & 0.12 \\
\hline Alanine aminotransferase, $\mathrm{U} / \mathrm{L}$ & $26(16-171)$ & $21(15-41)$ & 0.17 \\
\hline Aspartate aminotransferase, $\mathrm{U} / \mathrm{L}$ & $33(21-222)$ & $28(20-52)$ & 0.23 \\
\hline Alkaline phosphatase, $\mathrm{U} / \mathrm{L}$ & $82(58-134)$ & $85(54-142)$ & 0.93 \\
\hline Glutamine, $\mu \mathrm{mol} / \mathrm{L}$ & $486(374-702)$ & $469(357-701)$ & 0.66 \\
\hline
\end{tabular}

Table 3. Outcomes compared with admission vitamin D status

\begin{tabular}{llll}
\hline Outcomes & Vitamin D deficient, $<\mathbf{2 0} \mathbf{~ n g} / \mathbf{m L}$ & Vitamin D insufficient/sufficient, $\geq \mathbf{2 0} \mathbf{n g} / \mathbf{m L}$ & $\boldsymbol{p}_{\text {-value }}$ \\
\hline Length of ICU stay (days), median (IQR) & $7(5-9)$ & $6(4-12)$ & 0.91 \\
Length of hospital stay (days), median (IQR) & $11(8-24)$ & $13(7-22)$ & 0.80 \\
SOFA (day 7), median (IQR) & $5(2-10)$ & $2(1-4)$ & 0.017 \\
Mortality, $n$ (\%) & $11(16)$ & $4(11)$ & $0.77^{\dagger}$ \\
$\begin{array}{l}\text { ICU }=\text { intensive care unit; IQR }=\text { interquartile range, SOFA = sequential organ failure assessment. } \\
\text { Wilcoxon rank sum test, unless otherwise indicated. } \\
\text { 'Fisher's exact test. }\end{array}$
\end{tabular}

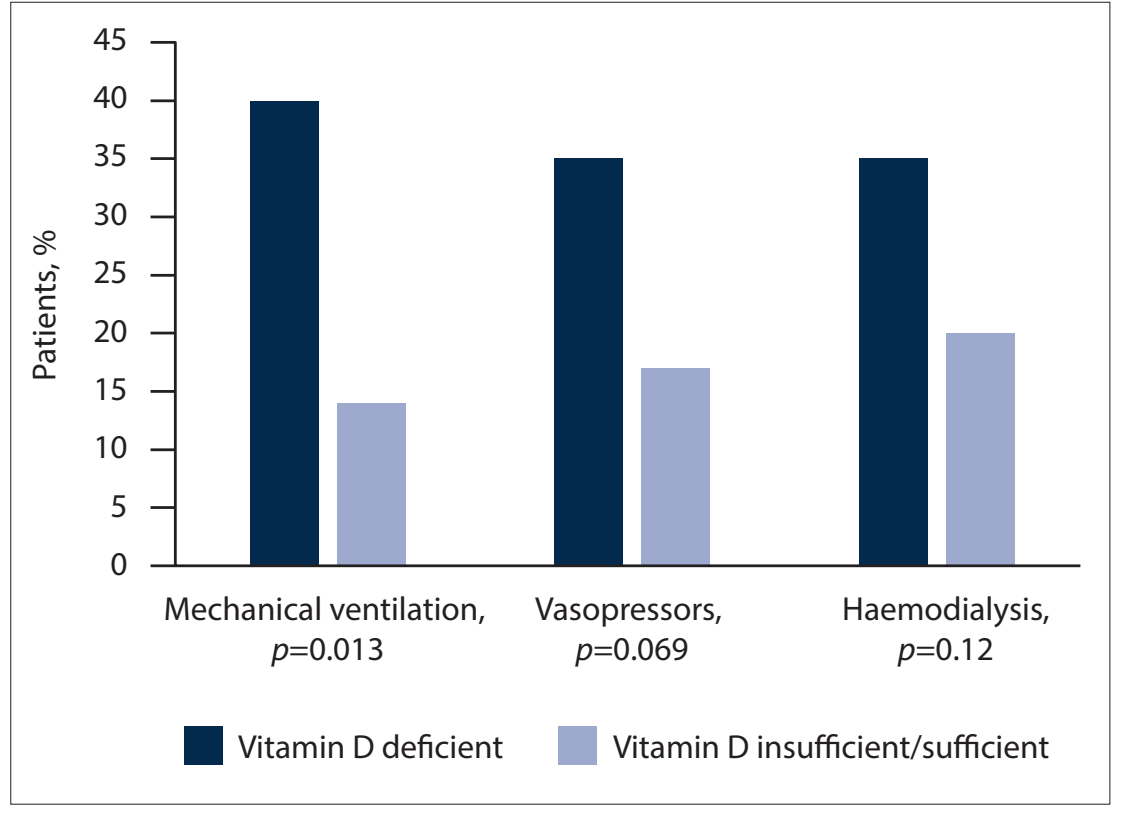

Fig. 2. Association between organ support and vitamin D status on admission to the ICU $(\mathrm{N}=103)$ (Fisher's exact test).

deficiency in critically ill patients remained high. ${ }^{[26]}$ Intriguingly, in populations with longer winter periods, where food fortification, consumption of fatty fish and use of supplements are greater owing to awareness around vitamin D status and its prevalence in our study. ${ }^{[27]}$ Individuals with high melanin levels of the skin notably have higher rates of vitamin $\mathrm{D}$ deficiency; however, we noted no racial differences regarding the prevalence of vitamin $\mathrm{D}$ deficiency in ICU patients. ${ }^{[27]}$

We observed higher illness severity scores and an increased need for mechanical ventilation among vitamin $\mathrm{D}$-deficient ICU patients, as in other observational studies. $^{[3,28-30)}$ Vitamin D has been shown to be protective to the alveolar epithelial layer and to reduce alveolar inflammation. ${ }^{[31,32]}$ Hence, the increased rates of mechanical ventilation we observed may be explained by loss of alveolar epithelial structural integrity in deficient patients. ${ }^{[31,32]}$ Despite the immunomodulatory function of vitamin $\mathrm{D}$, we observed no significant association between vitamin deficiency and inflammatory markers (CRP and PCT), which was also noted in some studies. ${ }^{[33,34]}$ However, our findings are in contrast with those in other studies, where patients with sepsis and vitamin D deficiency had a negative correlation between inflammatory markers and vitamin D levels. ${ }^{[29,30]}$ The absence of an association in our cohort may be explained by the absence of sepsis in many patients at initial presentation. 
$25(\mathrm{OH}) \mathrm{D}$ is produced in the liver after metabolism of vitamin $\mathrm{D}_{3}$ via the cytochrome $\mathrm{P} 450$ enzyme pathway. ${ }^{[3]}$ Patients with chronic liver disease are predisposed to vitamin $\mathrm{D}$ deficiency owing to numerous mechanisms, e.g. malnutrition, malabsorption, low levels of binding proteins and impaired hydroxylation of $25(\mathrm{OH}) \mathrm{D} \cdot{ }^{[3,35]}$ There was a high prevalence of vitamin $\mathrm{D}$ deficiency among patients with chronic liver disease (78\%), similar to the findings of Mayr et al. ${ }^{[35]}$ In their study, $72 \%$ of ICU patients with chronic liver disease were vitamin $\mathrm{D}$ deficient, with a greater prevalence among those with cirrhosis (74\%) compared with non-cirrhotic patients (45\%). Furthermore, they suggest that $25(\mathrm{OH}) \mathrm{D}$ levels $<10 \mathrm{ng} / \mathrm{dL}$ appear to be a risk factor for mortality in chronic liver disease, especially in patients with cirrhosis. Mayr et al. ${ }^{[35]}$ also noted that vitamin D supplementation prior to ICU admission reduced 180-day mortality (HR 0.46; 95\% CI $0.29-0.73 ; p<0.001$ ). However, following a post hoc analysis of the VITdAL-ICU RCT, there was no improvement in vitamin D levels or outcomes in critically ill patients with liver cirrhosis after vitamin D supplementation. This observation is limited by the small sample size $(n=23)$. Further research is necessary in patients with chronic liver disease, who have a high risk and prevalence of vitamin D deficiency, to determine if outcomes may be improved with vitamin D supplementation during critical illness. ${ }^{[36]}$

Vitamin D deficiency is associated with increased CRC risk, and improved CRC outcomes have been shown in a RCT following supplementation. ${ }^{[37]}$ Vitamin D levels were shown to decline in the immediate postoperative period in a Scottish cohort of 92 CRC patients. Furthermore, Vaughan-Shaw et al. ${ }^{[37]}$ performed a metaanalysis of 4106 patients, demonstrating that vitamin D deficiency was associated with increased postoperative CRC mortality (HR 0.69; 95\% CI 0.46 - 0.91) and all-cause mortality (HR 0.68; 95\% CI 0.50 0.85 ), which was independent of postoperative inflammation. In CRC patients with the VDR rs 11568820 GG genotype, increased mortality was associated with lower vitamin D levels (HR 0.51; 95\% CI 0.21 0.81). ${ }^{[37]}$ These findings support a causal relationship between a poorer outcome in CRC and vitamin D deficiency. As 54\% of our patients with CRC were vitamin D deficient, this lends support to the recommendation by Vaughan-Shaw et al. ${ }^{[37]}$ for a RCT on survival outcome with vitamin D supplementation after CRC surgery in deficient patients.

A recent study examined the metabolic profiles of critically ill patients in relation to early vitamin D status. Of interest, Lasky-Su et al..$^{[13]}$ noted that among those with $25(\mathrm{OH}) \mathrm{D}$ levels $<37.5 \mathrm{nmol} / \mathrm{L}(15 \mathrm{ng} / \mathrm{mL})$, and the presence of a systemic inflammatory response, metabolic pathways affecting glutamine metabolism were significantly altered. ${ }^{[3]}$ This interaction is of particular interest in critically ill patients. However, observational studies, meta-analyses and RCTs suggest the presence of a U-shaped relationship between glutamine levels and outcome, as both glutamine deficiency and excess levels are associated with worse outcomes. ${ }^{[18,38,39]}$ Therefore, it is pertinent to determine the influence of vitamin D on glutamine metabolism and ultimately serum glutamine levels, as this would further assist in clarifying any potential role of glutamine in critically ill patients. Despite the lack of an association between glutamine and vitamin D levels in this cohort of ICU patients, further studies are needed to clarify this potential interaction.

\section{Study limitations}

Our study is limited by the retrospective design and small study sample size, as well as the fairly unique and predominately postoperative patient population in our ICU. These factors, as well as the predominance of gastroenterology, hepatobiliary and renal pathology in our cohort, may make it difficult to extrapolate the findings to other ICUs. The large proportion of patients with chronic liver disease may have contributed to the low CRP levels. Furthermore, the measurement of $25(\mathrm{OH}) \mathrm{D}$ in CKD patients as opposed to 1.25 dihydroxyvitamin $\mathrm{D}$ may underestimate the prevalence of vitamin $\mathrm{D}$ deficiency in this population. The use of an immunoassay and not liquid chromatography-mass spectrometry to measure vitamin D levels is a potential limitation. Moreover, a comparison of glutamine and vitamin D levels after supplementation would be of value to clarify any potential metabolic relationship and implications of vitamin D supplementation on glutamine levels in a real-life clinical setting.

\section{Conclusions}

Despite high UVB light exposure in SA, vitamin D deficiency and glutamine deficiency are highly prevalent in patients on admission to the ICU. The vitamin D-deficient group was more severely ill and a greater number required mechanical ventilation. Despite a possible link between vitamin D and glutamine metabolism, no significant association between vitamin D levels and plasma glutamine concentration was observed.

\section{Declaration. None.}

Acknowledgements. The authors thank Ms Adele van der Merwe and Ms Madeleine Coetzee for their contribution to data collection for this study.

Author contributions. FS, GKS and RB conceptualised the study. FS collected the data and drafted the manuscript. PG analysed the data. GKS, PG and RB provided critical comments until final approval of the manuscript. All authors read and approved the final manuscript.

Funding. Fresenius Kabi Deutschland GmbH funded the measurement of glutamine levels and the Wits Donald Gordon Medical Centre funded the statistical analysis.

Conflicts of interest. None.

1. Williams S, Heuberger R. Outcomes of vitamin D supplementation in adults who are deficient and critically ill: A review of the literature. Am J Therapeutics 2016;23(6):e1890-e1902. https://doi. org/10.1097/MJT.0000000000000281

2. Amrein K, Venkatesh B. Vitamin D and the critically ill patient. Curr Opin Clin Nutr Metab Care Amrein K, Venkatesh B. Vitamin D and the critically ill patient. C
2012;15(2):188-193. https://doi.org/10.1097/MCO.0b013e32834fo027

3. Nair P, Venkatesh B, Center JR. Vitamin D deficiency and supplementation in critical illness - the known Nair P, Venkatesh B, Center JR. Vitamin D deficiency and supplementation in critical illness - the know
knowns and known unknowns. Crit Care 2018;22(1):276. https://doi.org/10.1186/s13054-018-2185-8

4. Azim A, Ahmed A, Yadav S, et al. Prevalence of vitamin D deficiency in critically ill patients and its influence on outcome: Experience from a tertiary care centre in North India. J Intens Care 2013;1(1):14. https://doi.org/10.1186/2052-0492-1-14

5. De Haan K, Groeneveld AB, de Geus HR, Egal M, Struijs A. Vitamin D deficiency as a risk factor for infection, sepsis and mortality in the critically ill: Systematic review and meta-analysis. Crit Care 2014;18(6):660. https://doi.org/10.1186/s13054-014-0660-4

6. Putzu A, Belletti A, Cassina T, et al. Vitamin D and outcomes in adult critically ill patients. A systematic review and meta-analysis of randomized trials. J Crit Care 2017;38:109-114. https://doi.org/10.1016/j. jcrc.2016.10.029

7. Zhang YP, Wan YD, Sun TW, Kan QC, Wang LX. Association between vitamin D deficiency and mortality in critically ill adult patients: A meta-analysis of cohort studies. Crit Care 2014;18(6):684. https://doi.org/10.1186/s13054-014-0684-9

8. Koekkoek WA, van Zanten AR. Vitamin D deficiency in the critically ill. Ann Med 2016;48(5):301-304. Koekkoek WA, van Zanten AR. Vitamin D defic
https://oi.org/10.3109/07853890.2016.1162910

9. Moraes RB, Friedman G, Wawrzeniak IC, et al. Vitamin D deficiency is independently associated with mortality among critically ill patients. Clinics (Sao Paulo) 2015;70(5):326-332. https://doi.org/10.6061/ clinics/2015(05)04

10. De Pascale G, Vallecoccia MS, Schiattarella A, et al. Clinical and microbiological outcome in septic patients with extremely low 25 -hydroxyvitamin D levels at initiation of critical care. Clin Microbiol Infect 2016;22(5):456.e7-456.e13. https://doi.org/10.1016/j.cmi.2015.12.015

11. Amrein K, Schnedl C, Holl A, et al. Effect of high-dose vitamin D3 on hospital length of stay in critically ill patients with vitamin D deficiency: The VITdAL-ICU randomized clinical trial. JAMA 2014;312(15):1520-1530. https://doi.org/10.1001/jama.2014.13204

12. Ginde AA, Brower RG, Caterino JM, et al. Early high-dose vitamin D3 for critically ill, vitamin D-deficient patients. N Engl J Med 2019;381(26):2529-2540. https://doi.org/10.1056/NEJMoa1911124

13. Lasky-Su J, Dahlin A, Litonjua AA, et al. Metabolome alterations in severe critical illness and vitamin D status. Crit Care 2017;21(1):193. https://doi.org/10.1186/s13054-017-1794-y

14. Novak F, Heyland DK, Avenell A, Drover JW, Su X. Glutamine supplementation in serious Novak F, Heyland DK, Avenell A, Drover JW, Su X. Glutamine supplementation in serious
illness: A systematic review of the evidence. Crit Care Med 2002;30(9):2022-2029. https://doi.
org/10.1097/00003246-200209000-00011

15. Lin JJ, Chung XJ, Yang CY, Lau HL. A meta-analysis of trials using the intention to treat principle for glutamine supplementation in critically ill patients with burn. Burns 2013;39(4):565-570. https://doi. org/10.1016/j.burns.2012.11.008 
16. Bollhalder L, Pfeil AM, Tomonaga Y, Schwenkglenks M. A systematic literature review and meta-analysis of randomized clinical trials of parenteral glutamine supplementation. Clin Nutr meta-analysis of randomized clinical trials of parenteral $\mathrm{g}$

17. Yue $C$, Tian $W$, Wang $W$, et al. The impact of perioperative glutamine-supplemented parenteral nutrition on outcomes of patients undergoing abdominal surgery: A meta-analysis of randomized nutrition on outcomes of patients undergoing abdominal surgery: A meta-analysis of rando
clinical trials. Am Surgeon 2013;79(5):506-513. https://doi.org/10.1177/000313481307900527

18. Heyland D, Muscedere J, Wischmeyer PE, et al. A randomized trial of glutamine and antioxidants in critically ill patients. N Engl J Med 2013;368(16):1489-1497. https://doi.org/10.1056/NEJMoa 1212722

19. Wernerman J. Glutamine supplementation to critically ill patients? Crit Care 2014;18(2):214. https:// doi.org/10.1186/cc1378

20. Wright CY, Norval M, Summers B, Davids LM, Coetzee G, Oriowo M. Solar ultraviolet radiation exposure and human health in South Africa: Finding a balance. S Afr Med J 2012;102(8):665-666 https://doi.org/10.7196/SAMJ.5921

1. Lim JU, Lee JH, Kim JS, et al. Comparison of World Health Organization and Asia-Pacific body mas index classifications in COPD patients. Int J Chron Obstruct Pulmon Dis 2017;12:2465-2475. https:// doi.org/10.2147/COPD.S141295

22. Quraishi SA, Camargo CA, Jr. Vitamin D in acute stress and critical illness. Curr Opin Clin Nut Metabol Care 2012;15(6):625-634. https://doi.org/10.1097/MCO.0b013e328358fc2b

23. Han JE, Jones JL, Tangpricha V, et al. High dose vitamin D administration in ventilated intensive care unit patients: A pilot double blind randomized controlled trial. J Clin Transl Endocrinol 2016;4:59-65. https://doi.org/10.1016/j.jcte.2016.04.004

24. Rodas PC, Rooyackers O, Hebert C, Norberg A, Wernerman J. Glutamine and glutathione at ICU admission in relation to outcome. Clin Sci 2012;122(12):591-597. https://doi.org/10.1042/CS20110520 5. Faul F, Erdfelder E, Lang AG, Buchner A. G*Power 3: A flexible statistical power analysis program for the social, behavioral, and biomedical sciences. Behav Res Method 2007;39(2):175-191. https://doi org/10.3758/bf03193146

26. Amrein K, Papinutti A, Mathew E, Vila G, Parekh D. Vitamin D and critical illness: What endocrinology can learn from intensive care and vice versa. Endocr Connect 2018;7(12):r304-r315. endocrinology can learn from inten

27. Palacios C, Gonzalez L. Is vitamin D deficiency a major global public health problem? J Steroid Biochem Molec Biol 2014;144:A138-A145. https://doi.org/10.1016/j.jsbmb. 2013.11.003

28. Nair P, Lee P, Reynolds C, et al. Significant perturbation of vitamin D-parathyroid-calcium axis and adverse clinical outcomes in critically ill patients. Intens Care Med 2013;39(2):267-274. https://doi org/10.1007/s00134-012-2713-y
29. Chen Z, Luo Z, Zhao X, et al. Association of vitamin D status of septic patients in intensive care units with altered procalcitonin levels and mortality. J Clin Endocrinol Metab 2015;100(2):516-523. https:// doi.org/10.1210/jc.2013-4330

30. Olejarova M, Dobisova A, Suchankova M, et al. Vitamin D deficiency - a potential risk factor for sepsis development, correlation with inflammatory markers, SOFA score and higher early mortality risk in sepsis. Bratisl Lek Listy 2019;120(4):284-290. https://doi.org/10.4149/BLL_2019_040

31. Dancer RC, Parekh D, Lax S, et al. Vitamin D deficiency contributes directly to the acute respiratory distress syndrome (ARDS). Thorax 2015;70(7):617-624. https://doi.org/10.1136/thoraxjnl-2014-206680

32. Yadav S, Joshi P, Dahiya U, et al. Admission vitamin D status does not predict outcome of critically ill patients on mechanical ventilation: An observational pilot study. Ind J Anaesth 2018;62(1):47-52. https://doi.org/10.4103/ija.IJA_531_17

3. Zhou W, Mao S, Wu L, Yu J. Association between vitamin D status and sepsis. Clin Lab 2018;64(4):451-460. https://doi.org/10.7754/Clin.Lab.2017.170919

34. Miroliaee AE, Salamzadeh J, Shokouhi S, et al. Effect of vitamin D supplementation on procalcitonin deficiency Iran J Parker in patients with ventilator associated pneumonia complicated wi

35. Mayr U, Fahrenkrog-Petersen L, Batres-Baires G, et al. Vitamin D deficiency is highly prevalent in critically ill patients and a risk factor for mortality: A prospective observational study comparing noncirrhotic patients and patients with cirrhosis. I Intens Care Med 2020;35(10):992-1001. https://doi.
nof org $/ 10.1177 / 0885066618803844$

36. Amrein K, McNally JD, Dobnig H, Pieber TR. High-dose cholecalciferol in critically ill patients with liver cirrhosis. J Intern Med 2016;279(3):309-310. https://doi.org/10.1111/joim.12457

37. Vaughan-Shaw PG, Zgaga L, Ooi LY, et al. Low plasma vitamin D is associated with adverse colorectal cancer survival after surgical resection, independent of systemic inflammatory response. Gut 2019;69:103-111. https://doi.org/10.1136/gutjnl-2018-317922

38. Gottschalk A, Wempe C, Goeters C. Glutamine in the ICU: Who needs supply? Clin Nutr 2013;32(4):668-669. https://doi.org/10.1016/j.clnu.2012.12.004

39. McNally JD. Vitamin D as a modifiable risk factor in critical illness: Questions and answers provided by observational studies. J Pediatr 2014;90(2):99-101. https://doi.org/10.1016/j.jped.2013.12.002

Accepted 3 June 2020 